\title{
Increased mortality among elderly patients with dementia using atypical antipsychotics
}

Published at www.cmaj.ca on July 13, 2005.

Reason for posting: Atypical antipsychotics are sometimes used to treat the behavioural disturbances (e.g., verbal or physical aggression) and psychotic symptoms that can occur in patients with severe dementia. ${ }^{1}$ CMAZ has previously issued warnings that specific agents (risperidone, olanzapine) may carry increased risk of fatal and nonfatal cerebrovascular events in patients with dementia. ${ }^{2,3}$ However, the US Food and Drug Administration (FDA) (www.fda.gov/cder /drug/infopage/antipsychotics /default.htm) and Health ¿ Canada (www.hc-sc.gc.ca/hpfb守 dgpsa/tpd-dpt/atyp-antipsycho ố_hpc-cps_e.html) have warned that results from several recent clinical trials suggest the drugs may increase mortality more generally and that this may be a class effect.

Table 1: Incidence of death among elderly patients with dementia in studies of 3 atypical antipsychotics*

\begin{tabular}{lrl}
\hline Antipsychotic & Total no. of patients & No. (\%) of deaths $\dagger$ \\
\hline Risperidone v. placeboł & 1009 v. 712 & $40(4.0)$ v. $22(3.1)$ \\
Quetiapine v. placebo§ & 365 v. 217 & $20(5.5)$ v. $7(3.2)$ \\
Olanzapine v. placebo & 1184 v. 478 & $42(3.5)$ v. $7(1.5)$
\end{tabular}

*Adapted from www.hc-sc.gc.ca/hpfb-dgpsa/tpd-dpt/atyp-antipsycho_hpc-cps_e.html. tDeaths from all causes.

‡Combined data from 6 trials.

$\S$ Combined data from 2 trials.

q Combined data from 5 trials.
The drugs: Atypical antipsychotics, including aripiprazole (Abilify), olanzapine (Zyprexa), quetiapine (Seroquel), risperidone (Risperdal), clozapine (Clozaril) and ziprasidone (Geodon), are used to treat schizophrenia. In Canada, only risperidone is indicated for treating behavioural disturbances associated with dementia.

Unfortunately, many of the trials reviewed by the FDA and Health Canada are unpublished, and details in the advisories are sparse (duration of the specific trials, baseline characteristics of the participants, doses used, specific causes of death and confidence intervals around point estimates are not provided). The FDA advisory describes 17 trials involving 5106 patients with dementia taking either placebo or 1 of 4 drugs (olanzapine, aripiprazole, risperidone or quetiapine). The trials averaged 10 weeks in duration. Mean mortality in the treatment group was $4.5 \%$ versus $2.6 \%$ in the placebo group (a relative risk increase of 1.7). Deaths were mostly due to cardiovascular events or infection. Some summary data from 13 of the trials involving drugs available in Canada are presented in Table 1.

What to do: Behavioural disturbances in advanced dementia are difficult for everyone to experience, and they seem to have no easy pharmacologic fix. Atypical antipsychotics are of questionable efficacy ${ }^{1,4}$ and safety in this population. Patients and their families must be warned of the 1.7 -fold increase in relative risk of death among those taking these agents over fairly short periods of time (only about 10 weeks). The increase in absolute risk appears to be about $1.9 \%$, giving a number needed to harm of 52. Because the risks of treatment may not be isolated to the first few months of use, the increase in absolute risk over longer treatment periods could be much higher, with much smaller numbers needed to harm. The prevalence of antipsychotic prescriptions translates to an enormous burden of mortality related to these drugs. The risk of death associated with older antipsychotic agents in this population is unclear. Nonpharmacologic measures (education of staff and families, specialized dementia wards) may be preferable ways of managing many behavioural disturbances.

\section{Sonal Singh}

Department of Medicine

Wake Forest University

Winston Salem, NC

Eric Wooltorton

CMAJ

\section{References}

1. Lee PE, Gill SS, Freedman M, Bronskill SE, Hillmer MP, Rochon PA. Atypical antipsychotic drugs in the treatment of behavioural and psychological symptoms of dementia: systematic review. BM7 2004;329:75-8.

2. Wooltorton E. Risperidone (Risperdal): increased rate of cerebrovascular events in dementia trials. CMA7 2002;167(11): 1269-70.

3. Wooltorton E. Olanzapine (Zyprexa) increased incidence of cerebrovascular events in dementia trials. CMAJ 2004;170(9):1395.

4. Sink KM, Holden KF, Yaffe K. Pharmacological treatment of neuropsychiatric symptoms of dementia. A review of the evidence. FAMA 2005;293:596-608. 